Article

\title{
The Effect of Heat Treatment on the Sensitized Corrosion of the 5383-H116 Al-Mg Alloy
}

\author{
Ying-Kai Lin ${ }^{1}$, Shing-Hai Wang ${ }^{2}$, Ren-Yu Chen ${ }^{3}$, Tso-Sheng Hsieh ${ }^{1}$, Liren Tsai ${ }^{1}$ and \\ Chia-Chin Chiang ${ }^{1, *}$ \\ 1 Department of Mechanical Engineering, National Kaohsiung University of Applied Sciences, \\ Kaohsiung City 807, Taiwan; u8812331@gmail.com (Y.-K.L.); \\ srcx2s904@gmail.com (T.-S.H.); liren@kuas.edu.tw (L.T.) \\ 2 Department of Electrical Engineering, Fortune Institute of Technology, No. 28, Zhixue Rd., Daliao Dist., \\ Kaohsiung City 831, Taiwan; shing-hae_wang@hotmail.com \\ 3 Naval Shipbuilding Development Center, Navy Command R.O.C., Taipei City 104, Taiwan; \\ renyu.tw@gamil.com \\ * Correspondence: ccchiang@kuas.edu.tw; Tel.: +886-07-381-4526 (ext. 5340)
}

Academic Editor: Chien-Hung Liu

Received: 27 December 2016; Accepted: 6 March 2017; Published: 9 March 2017

\begin{abstract}
In this study, the effects of heat treatment and sensitized corrosion on the 5383-H116 Al-Mg alloy were investigated for temperatures ranging from 100 to $450{ }^{\circ} \mathrm{C}$. The results show that the heat treatment temperature is the main factor that causes changes to the microstructure and mechanical strength of the 5383-H116 Al-Mg alloy, inducing $\beta$-phase $\left(\mathrm{Al}_{3} \mathrm{Mg}_{2}\right)$ precipitation in the form of a continuous layer along the grain boundaries. Intergranular corrosion was caused by the $\beta$-phase of the grain boundary precipitation, and the corrosion susceptibility of the recrystallized structure was significantly higher than the corrosion susceptibility of the recovered structure. According to the conductivity values detected, $\beta$-phase precipitation can enhance the $5383-\mathrm{H} 116 \mathrm{Al}-\mathrm{Mg}$ alloy conductivity, with the response due to structural dislocation density being higher than that due to the recrystallized structure. As such, the $\beta$-phase precipitation after sensitization is more significant than the $\beta$-phase precipitation prior to the sensitization, such that after sensitization, the conductivity rises to a significantly higher level than that exhibited by the recrystallization structure.
\end{abstract}

Keywords: 5383-H116 Al-Mg alloy; sensitization; NAMLT; $\beta$ phase- $\mathrm{Al}_{3} \mathrm{Mg}_{2}$

\section{Introduction}

The 5XXX series Al-Mg alloy is known to be lightweight, easy to machine, and high in strength, among other attributes [1,2]. Since the 1950s, large amounts of the alloy have been used in the structures of ships due to its excellent corrosion resistance when immersed in seawater [3,4]. Use of the alloy allowed the weights of vessels produced with it to be significantly reduced, an improvement which translated into fuel savings and associated environmental advantages [5]. However, the applications of aluminum and its alloys in this field were far less advanced than those of various steels because of cost and formability issues at room temperature [6]. Marine applications for Al-Mg alloys are mainly divided into the construction of ship frames and outfitting. The aluminum materials used by each shipyard differ according to the ship design and the task requirements. ASTM B928 standards state that the 5086, 5083, 5383, 5456, and 5059 Al-Mg alloys and H116 and H321 Al-Mg tempers are suitable for marine service. H116 temper plates are manufactured and hardened using cold rolling, while H321 temper plates are stabilized by low-temperature heating after the hardening process in order to cause the $\beta$-phase to be evenly spread through the Al matrix, thus improving the intergranular corrosion and stripping resistances. The main alloying element in marine $\mathrm{Al}-\mathrm{Mg}$ alloys is $\mathrm{Mg}$; the strength increases 
as the amount of Mg increases [7]. Popović [8] proposed that the change in the differential dislocation density during the recovery or recrystallization has little effect on the conductivity, and the main difference is due to the solid solution or precipitation of the $\beta$-phase. The primary corrosion problems of $\mathrm{Al}-\mathrm{Mg}$ alloys, in which the $\beta$-phase $\mathrm{Al}_{3} \mathrm{Mg}_{2}$ has a temperature range of $50-200{ }^{\circ} \mathrm{C}$, will gradually result in a sensitization phenomenon due to the formation of $\beta$-phase layers at the grain boundaries. In this study, we observed microstructure changes and used the nitric acid mass loss test (NAMLT), known as the ASTM G67-13 NAMLT, to investigate the corrosion characteristics of the 5383-H116 Al-Mg alloy [9].

\section{Literature and Theory}

\subsection{Al-Mg Alloy Sensitization Characteristics}

ASTM B928 defines Al-Mg alloy sensitization as the precipitation of the $\beta$-phase at the grain boundaries [10]. When the density of $\beta$-phase precipitates increases, the degree of sensitization (DoS) also increases. Under corrosive or stressful conditions, this leads to intergranular corrosion and stress corrosion. In addition, as the DoS within the microstructure cannot be exactly determined, ASTM B928 requires Al-Mg alloy to be subject to the ASTM G67-13 NAMLT [11] to measure the mass loss during corrosion in order to ascertain the DoS. A mass loss of less than $15 \mathrm{mg} / \mathrm{cm}^{2}$ is considered not sensitized, a mass loss of between 15 and $25 \mathrm{mg} / \mathrm{cm}^{2}$ is considered partially sensitized, and a mass loss of over $25 \mathrm{mg} / \mathrm{cm}^{2}$ is considered sensitized.

\section{2. $\beta$-Phase Precipitation Characteristics and Effects on Corrosion}

\subsubsection{Influence of $\mathrm{Mg}$ Content on $\beta$-Phase Precipitation}

Gupta et al. [12] examined the NAMLT mass loss and $\beta$-phase precipitation of Al-Mg alloys with varying $\mathrm{Mg}$ contents after sensitization treatment $\left(150{ }^{\circ} \mathrm{C} / 7\right.$ days) and found that with a $\mathrm{Mg}$ content $>4 \mathrm{wt}$. \%, the mass loss increased linearly and the proportion of the $\beta$-phase precipitation increased as the $\mathrm{Mg}$ content increased. Dix et al. [13] investigated the influence of $\mathrm{Mg}$ content on Al-Mg alloy sensitization and stress corrosion and found potential differences between the precipitates and the $\mathrm{Al}$ matrix, leading them to propose the $\mathrm{Al}-\mathrm{Mg}$ alloy anodic dissolution stress corrosion mechanism wherein the stress corrosion sensitivity increases as the $\mathrm{Mg}$ content increases. Czyryca et al. [14] tested 5086, 5083, and $5456 \mathrm{Al}-\mathrm{Mg}$ alloys for corrosion when soaked in saltwater, when salt-spray tested, and under harbor exposure conditions. The results showed that the degree of corrosion and the $\mathrm{Mg}$ content were directly proportional, with the 5086 alloy experiencing the lowest level of corrosion, followed by the 5083 and 5456 alloys.

\subsubsection{Influence of Sensitization Temperature and Time on $\beta$-Phase Precipitation}

Searles et al. [15] pointed out that the sensitization temperatures of 5XXX Al-Mg alloys are between 50-200 ${ }^{\circ} \mathrm{C}$ and that different sensitization temperatures and isothermal holding times cause different amounts of corrosion. In addition, the sensitization temperature range and isothermal holding time are the main factors influencing Al-Mg alloy $\beta$-phase precipitation. Oguocha et al. [16] tested the corrosion resistance of $5083-\mathrm{H} 116$ at $80,100,150,175$, and $200{ }^{\circ} \mathrm{C}$ and at different heating times and found that the $150-200^{\circ} \mathrm{C}$ range caused high sensitization, with the most sensitization and corrosion mass loss occurring at $175^{\circ} \mathrm{C}$. They also noted that in a corrosive environment, mass loss increases as the isothermal holding time increases. Jones et al. [17] investigated the corrosion of 5083-H321 at $175{ }^{\circ} \mathrm{C}$ with different heating times and concluded that as the heating time increased within the $50-200{ }^{\circ} \mathrm{C}$ sensitization range, the $\beta$-phase precipitation became more dense and connected and the fissure growth rate increased; thus, the $\beta$-phase precipitation density increased and the stress corrosion became more significant. Lim et al. [18] investigated the $5083 \mathrm{Al}-\mathrm{Mg}$ alloy intergranular corrosion permeation depth and the relationship between the electrochemical corrosion environment and metallurgy conditions 
and found that the $\beta$-phase corrosion depth and sensitization time were directly proportional and affected by the grain direction, specifically that corrosion permeated following the rolling direction.

\section{Experiment Setup}

This study used 6-mm-thick 5383-H116 Al-Mg alloy plates produced by Alcan incorporation. Prior to the experiment, the composition of the sample was analyzed using a glow discharge spectrometer (GDS) as shown in Table 1.

Table 1. The components of 5383-H116 Al-Mg alloy (wt. \%).

\begin{tabular}{cccccccccc}
\hline Element & Si & Fe & Cu & Mn & Mg & Cr & Zn & Ti & Al \\
\hline $5383-H 116$ & 0.07 & 0.21 & 0.09 & 0.81 & 4.70 & 0.08 & 0.08 & 0.02 & remainder \\
\hline
\end{tabular}

\subsection{Heat Treatment Stage}

5383-H116 aluminum alloys were cut into cubes $(10 \mathrm{~mm} \times 10 \mathrm{~mm} \times 10 \mathrm{~mm}$ for optical microscope $(\mathrm{OM})$ and scanning electron microscopy (SEM) ) and cuboids $(6 \mathrm{~mm} \times 6 \mathrm{~mm} \times 10 \mathrm{~mm}$, for ASTM G-67 mass loss test), and subsequently placed in ovens for isothermal aging experiments. The aging temperatures were set to $25,100,150,200,250,300,350,400$ and $450{ }^{\circ} \mathrm{C}$ (the heating rate was about $10^{\circ} \mathrm{C} / \mathrm{min}$ and the temperature of the ovens was controlled to within $0.5^{\circ} \mathrm{C}$ ) to produce microstructure changes in the alloys and held there for $30 \mathrm{~min}$ before quenching of the alloys was performed in room temperature water. The heat treated test samples then underwent sensitization treatment at $175^{\circ} \mathrm{C}$ for $168 \mathrm{~h}$ and were then water quenched. After the $\beta$-phase precipitated, the samples were analyzed under a microscope, underwent corrosion testing, and were measured for electrical conductivity.

\subsection{Corrosion Testing}

According to ASTM G67, the dimensions of the test specimen were $50 \mathrm{~mm} \times 6 \mathrm{~mm} \times 6 \mathrm{~mm}$, and the specimen was soaked in $5 \% \mathrm{NaOH}$ solution at $80{ }^{\circ} \mathrm{C}$ to remove the surface oxidation and impurities. This was followed by its continuous immersion in $\mathrm{HNO}_{3}$ solution at $30{ }^{\circ} \mathrm{C}$ for $24 \mathrm{~h}$ to calculate the weight loss per unit area $\left(\mathrm{mg} / \mathrm{cm}^{2}\right)$, which allowed, in turn, for the evaluation of the sensitivity of the intergranular corrosion.

\subsection{Measuring Electrical Conductivity}

By measuring the electrical conductivity, it is possible to assess the microstructure of the alloy and the changes in $\beta$ phase precipitation. This study used a Sigmascope SMP10 (Fischer Technology, Inc., Windsor, CT, USA) for electrical conductivity measurement. Calibration was completed before the experiment using the International Annealed Copper Standard (IACS); the unit of this test was \% IACS. After calibration, the electrical conductivity of each test strip was measured to investigate the changes in conductivity in alloys manufactured with different heat treatments and different sensitivities.

\section{Results and Discussion}

\subsection{Microstructure Changes Resulting from the Heat Treatment}

The overall microstructure was similar to the original material during the recovery phase from 25-300 ${ }^{\circ} \mathrm{C}$ and there were no noticeable changes. The grains were still fibrous and distributed in the direction of rolling (Figure $1 \mathrm{~b}-\mathrm{f}$ ). When the temperature surpassed the recrystallization temperature, some grains were ready for nucleation and growth. Fibrous grain structures and small recrystallized structures can both be seen in Figure 1f; the dislocations would be eliminated during the recrystallization process and small grains without strain would be nucleated. At a temperature of $350{ }^{\circ} \mathrm{C}$, the microstructure was already made up of strainless, equiaxed grains. At $450{ }^{\circ} \mathrm{C}$, the equiaxed recrystallized structure was maintained, indicating that the high temperature provided sufficient 
energy to completely release the stored strain energy. The results indicated that suitable heat treatment temperatures are lower than the recovery temperature of $250{ }^{\circ} \mathrm{C}$, as no major changes to the microstructure occurred when the samples were treated at such temperatures. When the temperature was over $300{ }^{\circ} \mathrm{C}$, however, the microstructure recrystallized and the mechanical strength decreased. Heat treatment temperatures of $65-200{ }^{\circ} \mathrm{C}$ caused $\beta$-phase precipitation and sensitization. In a corrosive environment, this will cause intergranular corrosion and stress corrosion.

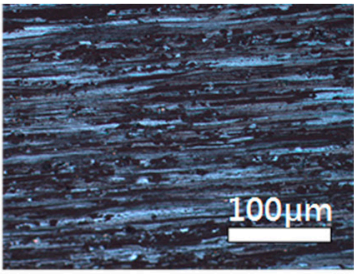

(a) $25^{\circ} \mathrm{C}$ (Base metal)

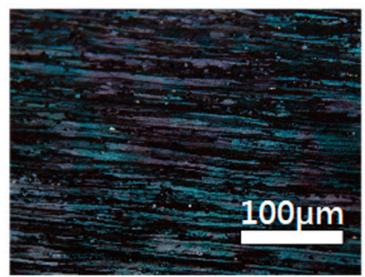

(d) $200^{\circ} \mathrm{C}$

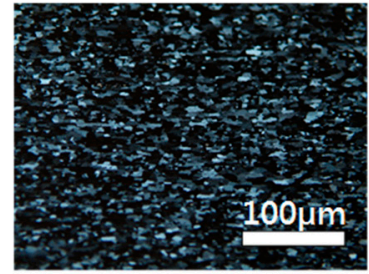

(g) $350^{\circ} \mathrm{C}$

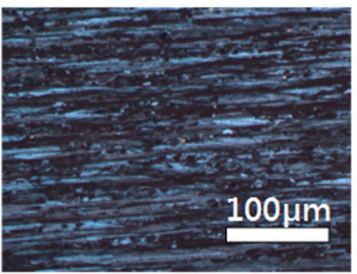

(b) $100^{\circ} \mathrm{C}$

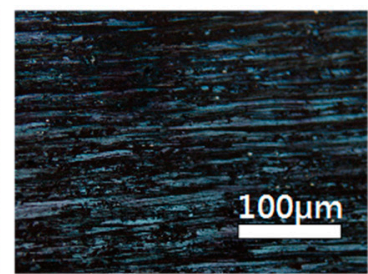

(e) $250^{\circ} \mathrm{C}$

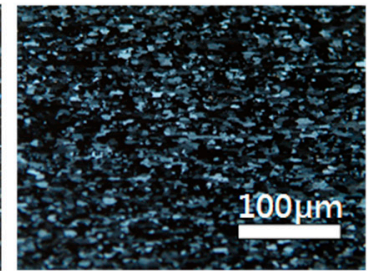

(h) $400^{\circ} \mathrm{C}$

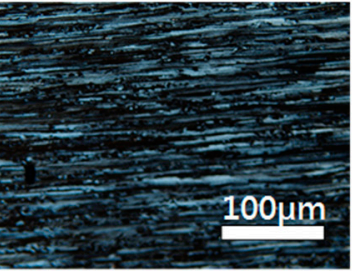

(c) $150^{\circ} \mathrm{C}$

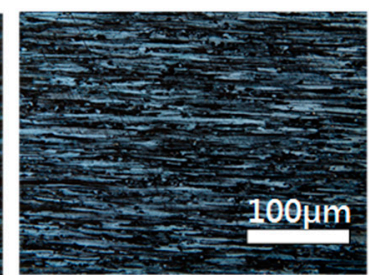

(f) $300^{\circ} \mathrm{C}$

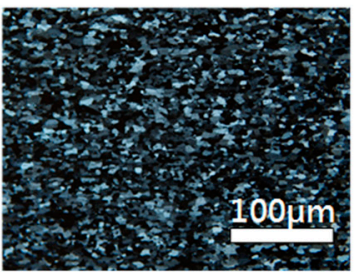

(i) $450^{\circ} \mathrm{C}$

Figure 1. OM images of 5383-H116 Al-Mg alloy at different heat treatment temperatures. (a) $25^{\circ} \mathrm{C}$; (b) $100{ }^{\circ} \mathrm{C}$; (c) $150{ }^{\circ} \mathrm{C}$; (d) $200{ }^{\circ} \mathrm{C}$; (e) $250{ }^{\circ} \mathrm{C}$; (f) $300{ }^{\circ} \mathrm{C}$; (g) $350{ }^{\circ} \mathrm{C}$; (h) $400{ }^{\circ} \mathrm{C}$; (i) $450{ }^{\circ} \mathrm{C}$.

\subsection{Influence of Sensitization on Microstructure and Mechanical Properties}

After sensitization treatment, different microstructure patterns were produced due to the different heat treatment temperatures. Also, because the $\beta$-phase underwent heterogeneous nucleation at high energy regions, the microstructure patterns first precipitated at the grain boundaries, then dislocated, and finally precipitated within the grain. The $\beta$-phase precipitation indicated that the sensitization temperature only caused the $\beta$-phase to precipitate and did not change the heat treatment structure. Within the recovery temperature range, the sensitized appearance was still fiber-shaped. At a heat treatment temperature greater than the recrystallization range, the sensitized microstructure transformed from partially recrystallized to fully recrystallized. The 5383-H116 Al-Mg alloy $\beta$-phase precipitation at $25-450{ }^{\circ} \mathrm{C}$ is shown in Figure 2. Figure 3 shows the $\beta$-phase precipitations for each heat treatment after sensitization $\left(175^{\circ} \mathrm{C} / 168 \mathrm{~h}\right)$.

The results of the stretching tests for the 5383-H116 Al-Mg alloy heat-treated from $25{ }^{\circ} \mathrm{C}$ to $450{ }^{\circ} \mathrm{C}$ are shown in Figure 4. The Yield Strength (YS) fell by varying degrees as the heat treatment temperature rose. The highest YS was $214 \mathrm{MPa}$. If the heat treatment temperature was within the recovery period, the loss of tensile strength was negligible; however, as the number of dislocations decreased, creating dislocations with low strain energy, the ductility of the material was increased. 


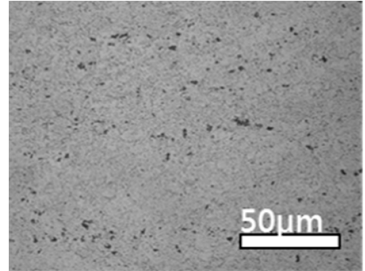

(a) $25^{\circ} \mathrm{C}$ (Base metal)

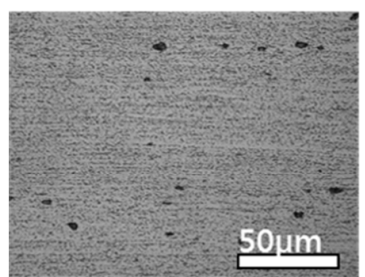

(d) $200^{\circ} \mathrm{C}$

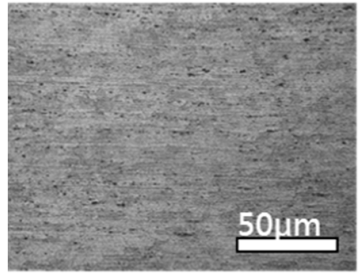

(g) $350^{\circ} \mathrm{C}$

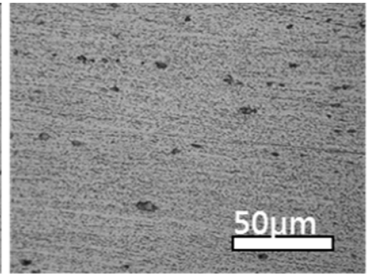

(b) $100^{\circ} \mathrm{C}$

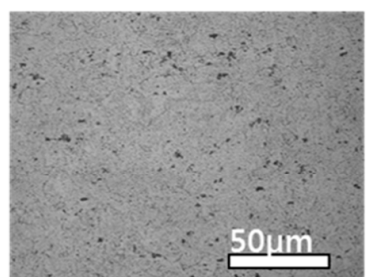

(e) $250^{\circ} \mathrm{C}$

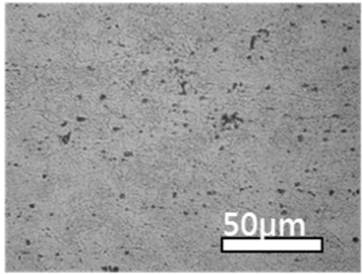

(h) $400^{\circ} \mathrm{C}$

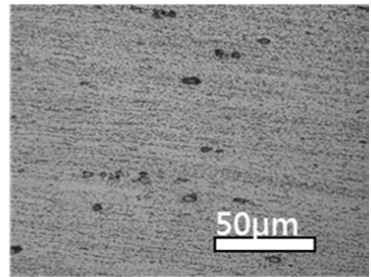

(c) $150^{\circ} \mathrm{C}$

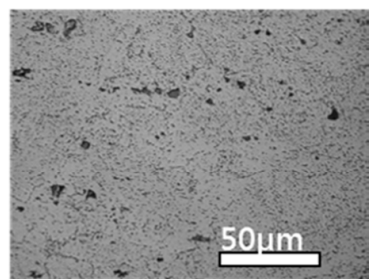

(f) $300^{\circ} \mathrm{C}$

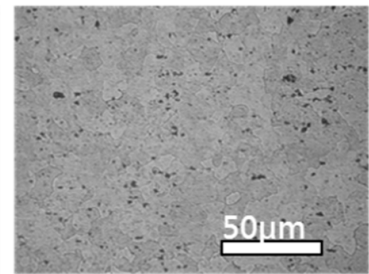

(i) $450^{\circ} \mathrm{C}$

Figure 2. $\mathrm{OM}$ images of 5383-H116 $\mathrm{Al}-\mathrm{Mg}$ alloy $\beta$-phase precipitation at different annealing temperatures. (a) $25^{\circ} \mathrm{C}$; (b) $100{ }^{\circ} \mathrm{C}$; (c) $150{ }^{\circ} \mathrm{C}$; (d) $200{ }^{\circ} \mathrm{C}$; (e) $250{ }^{\circ} \mathrm{C}$; (f) $300{ }^{\circ} \mathrm{C}$; (g) $350{ }^{\circ} \mathrm{C}$; (h) $400{ }^{\circ} \mathrm{C}$; (i) $450{ }^{\circ} \mathrm{C}$.

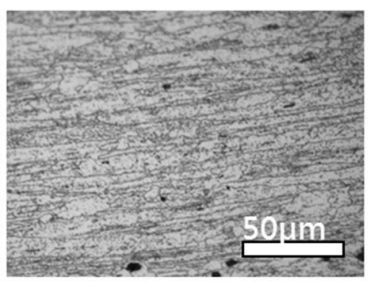

(a) $25^{\circ} \mathrm{C}$ (Base metal)

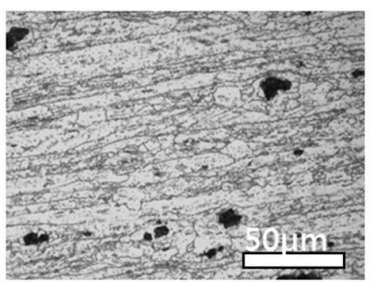

(d) $200^{\circ} \mathrm{C}$

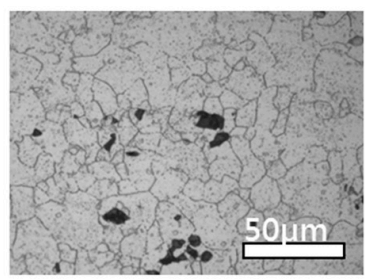

(g) $350^{\circ} \mathrm{C}$

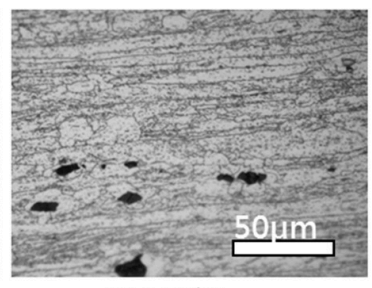

(b) $100^{\circ} \mathrm{C}$

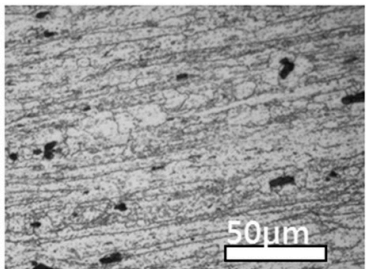

(e) $250^{\circ} \mathrm{C}$

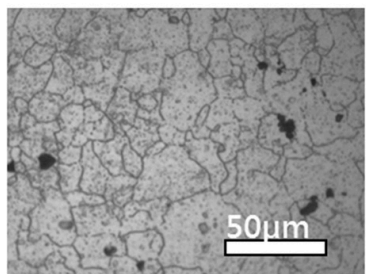

(h) $400^{\circ} \mathrm{C}$

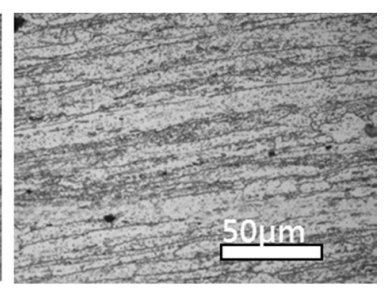

(c) $150^{\circ} \mathrm{C}$

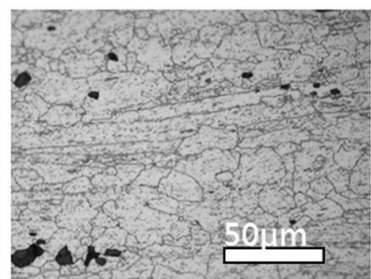

(f) $300^{\circ} \mathrm{C}$

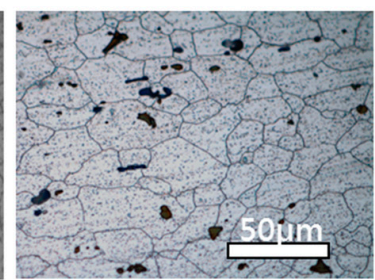

(i) $450^{\circ} \mathrm{C}$

Figure 3. OM images of 5383-H116 Al-Mg alloy $\beta$-phase precipitation at different annealing temperatures after $175^{\circ} \mathrm{C} / 168 \mathrm{~h}$ sensitization. (a) $25^{\circ} \mathrm{C}$; (b) $100{ }^{\circ} \mathrm{C}$; (c) $150{ }^{\circ} \mathrm{C}$; (d) $200{ }^{\circ} \mathrm{C}$; (e) $250{ }^{\circ} \mathrm{C}$; (f) $300{ }^{\circ} \mathrm{C}$; (g) $350{ }^{\circ} \mathrm{C}$; (h) $400{ }^{\circ} \mathrm{C}$; (i) $450{ }^{\circ} \mathrm{C}$. 


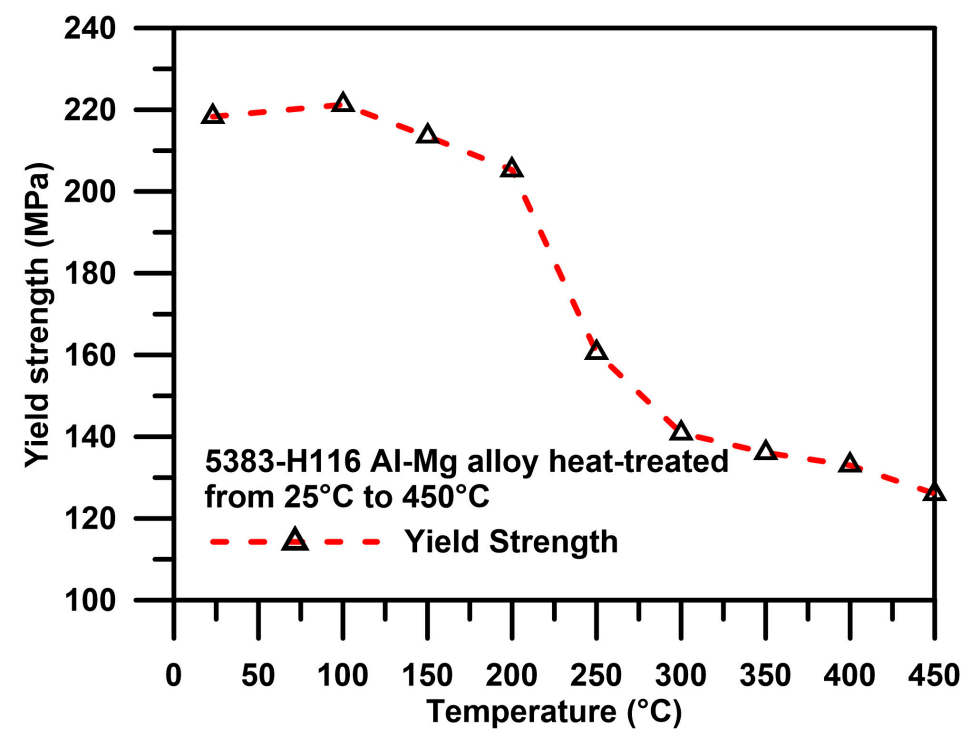

Figure 4. 5383-H116 tension test results after different annealing and sensitization treatment.

\subsection{Influence of Heat Treatment and Sensitization Treatment on Intergranular Corrosion Sensitivity}

The 5383-H116 Al-Mg alloy test strips heat treated at $25-450{ }^{\circ} \mathrm{C}$ for $30 \mathrm{~min}$ experienced weight loss within the acceptable parameters $\left(<25 \mathrm{mg} / \mathrm{cm}^{2}\right)$, indicating that microstructure transformation did not greatly affect the corrosion resistance. The heat-treated test samples then underwent sensitization treatment at $175{ }^{\circ} \mathrm{C}$ for $168 \mathrm{~h}$ and were then water-quenched. After the $\beta$-phase precipitated, the samples were analyzed under a microscope. Under all heat treatment conditions, the mass loss for the 5383-H116 Al-Mg alloy after sensitization treatment was greater than $25 \mathrm{mg} / \mathrm{cm}^{2}$, exceeding the ASTM G67-13 NAMLT standards. Figure 5 shows the 5383-H116 Al-Mg alloy intergranular corrosion sensitivity, with the recrystallized structure clearly greater than the recovery structure. Thus, the $\beta$-phase is the main factor that affects intergranular corrosion sensitivity, and the microstructure is the secondary factor that determines intergranular corrosion sensitivity.

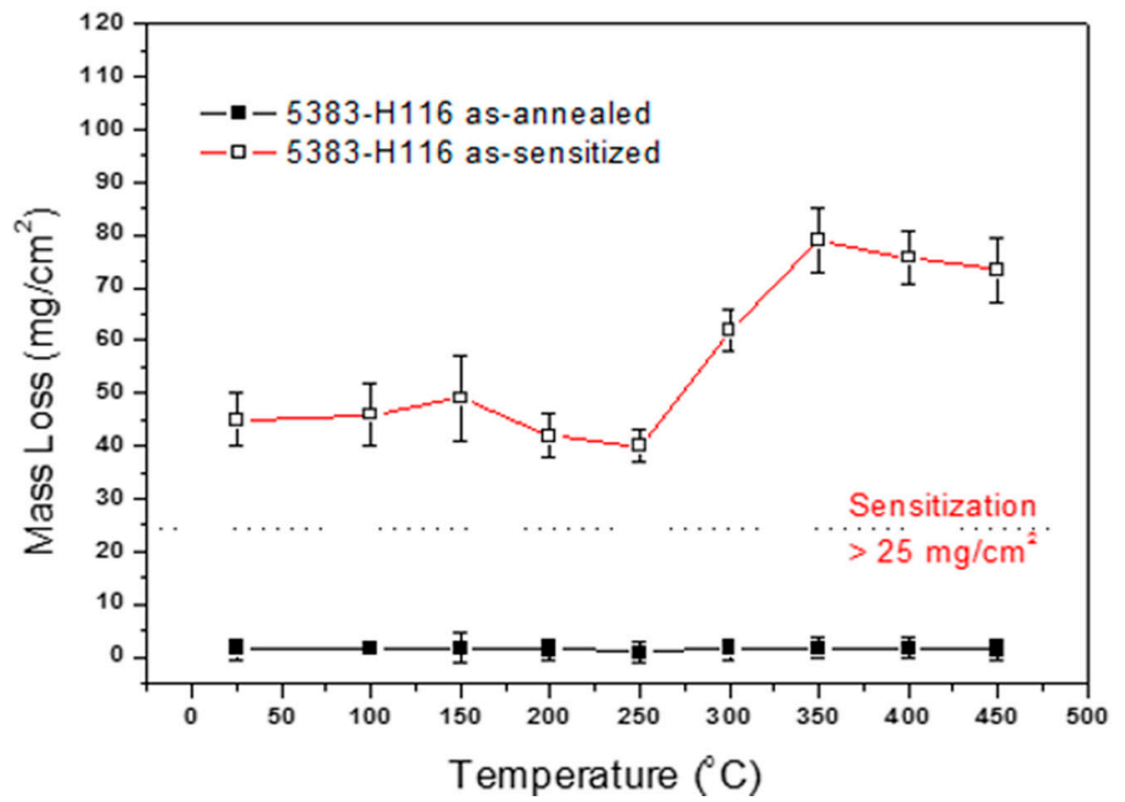

Figure 5. The 5383-H116 NAMLT test results after different heat treatment temperatures and sensitization treatment. 
The results above show that the $\beta$-phase has heterogeneous nucleation at areas of high energy and precipitates first. The $\beta$-phase tends to precipitate at grain boundaries regardless of recovery or recrystallization structures. The NAMLT results indicate that the recrystallized structure mass loss is higher than that for recovery structures; therefore, DoS in the recrystallized structure was greater than that in the recovery structure. After the $\beta$-phase precipitates and corrodes, the eroded unit volume is greater in recrystallized structures than in recovered structures, leading to greater weight loss in recrystallized structures.

\subsection{Changes in Electrical Conductivity during the Sensitization Process}

The differences in the relative electrical conductivity between 5383-H116 Al-Mg alloys at different heating treatment temperatures before and after sensitization treatment $\left(\Delta_{\sigma s}\right)$ are shown in Figure 6.

$$
\Delta_{\sigma \mathrm{s}}=\left(C_{\text {as-sensitized }}-C_{\text {as-annealed }}\right) / C_{\text {as-annealed }} \times 100 \%
$$

where $C_{\text {as-sensitized }}$ is the electrical conductivity of the heat-treated alloy after sensitization. As shown in the figure, the microstructure transformation did not greatly affect the electrical conductivity, although the electrical conductivity of the heat-treated alloys was increased after sensitization.

The increased electrical conductivity in the recovery structure was greater than in the recrystallized structure because the dislocation density in the recovery structure is greater than the recrystallized structure as the $\beta$-phase undergoes heterogeneous nucleation at dislocation areas and the dislocation tube transfer effect diffuses the $\mathrm{Mg}$, i.e., a higher dislocation density increases the rate and amount of $\beta$-phase precipitation. Mulazimoglu et al. [19] also pointed out that the increase in the Mg content will reduce the conductivity of the alloy due to a large number of supersaturated $\mathrm{Mg}$ atoms being dissolved in the aluminum base, which causes damage to the original lattice arrangement and, thus, significantly hinders its free electron path, thereby reducing the conductivity. According to the Al-Mg binary phase diagram, the $\beta$-phase precipitation can be a solution in aluminum by annealing the alloys at elevated temperatures exceeding $250{ }^{\circ} \mathrm{C}$.

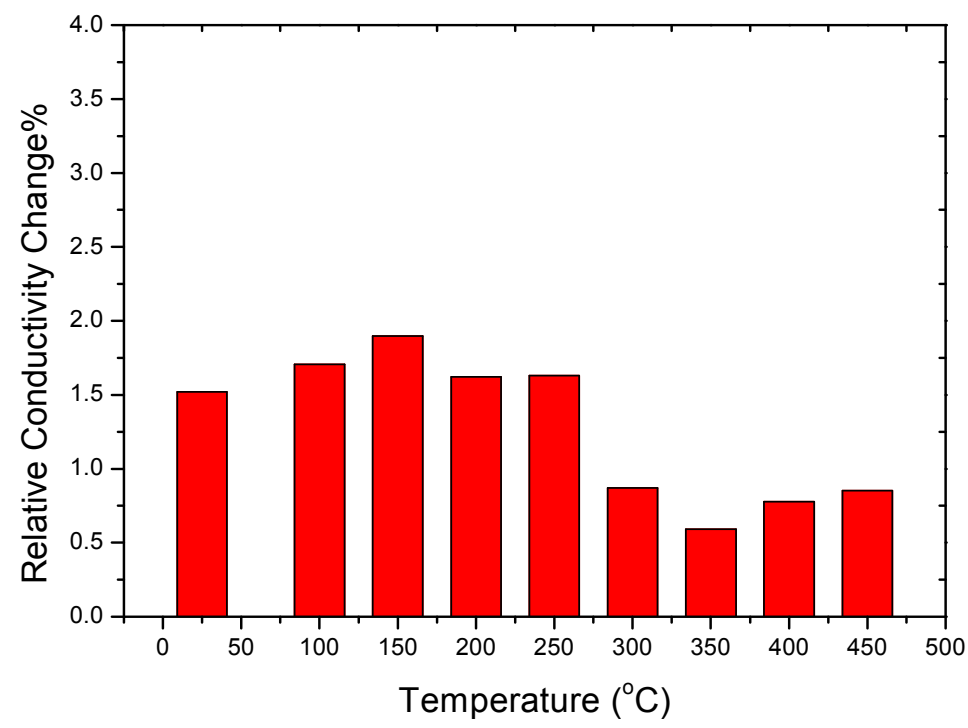

Figure 6. Differences in electrical conductivity in 5383-H116 NAMLT after different heat treatment conditions and sensitization treatment.

\subsection{NAMLT Corrosion}

Continuous $\beta$-phase precipitation provides a pathway for corrosion transmission. The appearance of SEM images of corrosion in 5383-H116 after different heat treatment conditions and sensitization 
treatment is shown in Figure 7. The corrosion of the 5383-H116 Al-Mg alloy clearly shows that the post-heat treatment microstructure is correlated with the differences in corrosion. Corrosion in the recovery structures was mainly fiber-like in appearance. Corrosion in partly recrystallized structures was partly fiber-like and partly granular in appearance. Finally, corrosion in the fully recrystallized structures was completely granular.
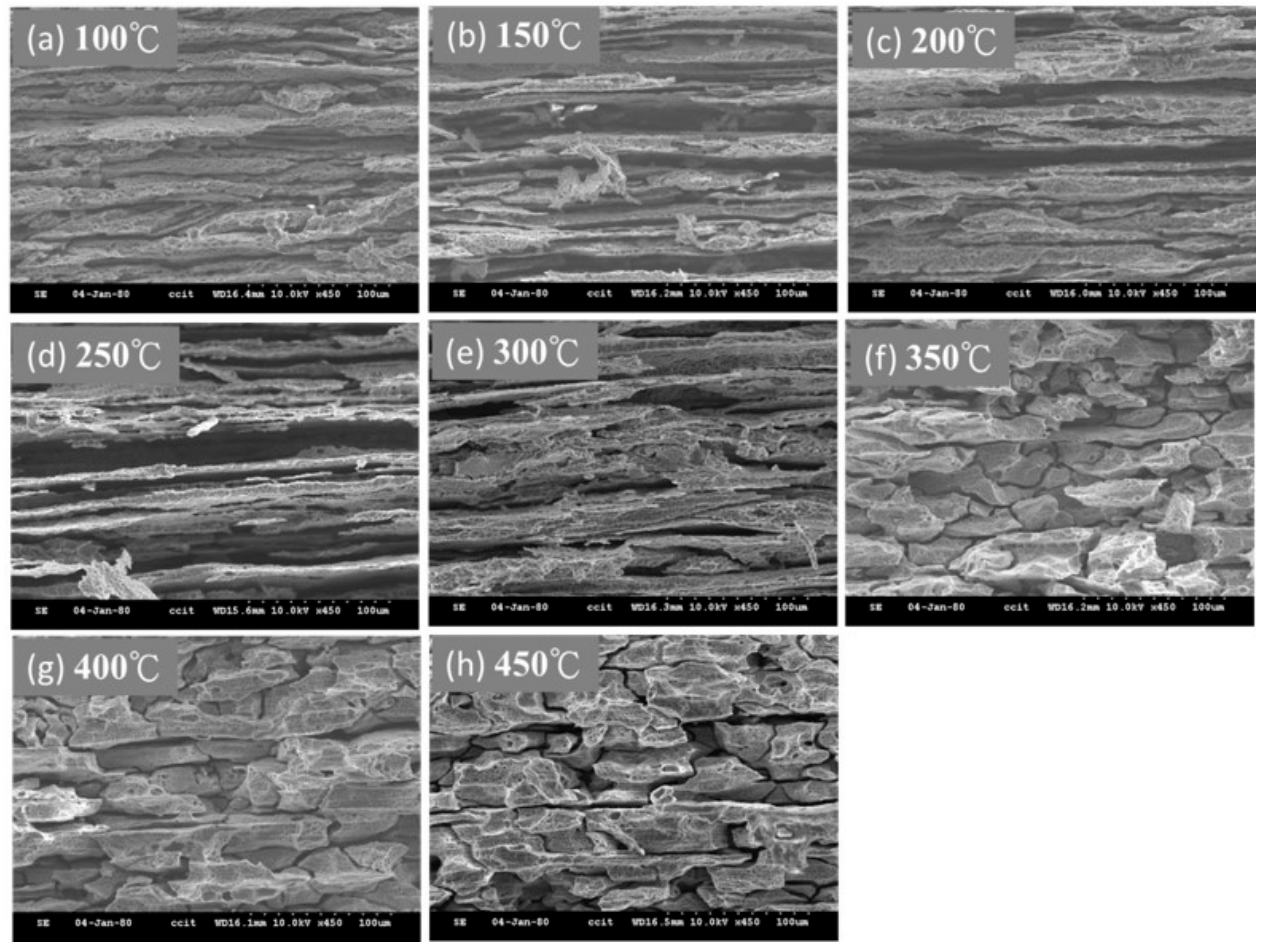

Figure 7. SEM images of corrosion in 5383-H116 after different heat treatment conditions and sensitization treatment. (a) $100{ }^{\circ} \mathrm{C}$; (b) $150{ }^{\circ} \mathrm{C}$; (c) $200{ }^{\circ} \mathrm{C}$; (d) $250{ }^{\circ} \mathrm{C}$; (e) $300{ }^{\circ} \mathrm{C}$; (f) $350{ }^{\circ} \mathrm{C}$; (g) $400{ }^{\circ} \mathrm{C}$; (h) $450{ }^{\circ} \mathrm{C}$.

\section{Conclusions}

This study elucidates how heat treatment affects the mechanical properties and sensitization of 5383-H116 aluminum alloys. The following conclusions are drawn from the above analysis.

1. The heat treatment temperature is an important factor affecting 5383-H116 Al-Mg alloy microstructure changes. When the treatment temperature exceeds $300{ }^{\circ} \mathrm{C}$, the structure begins to recrystallize, which decreases the mechanical strength.

2. The DoS of the recrystallized structure is bigger than that of the recovery structure; therefore, in the same sensitized environment, the recrystallized structure will be more susceptible to intergranular corrosion than the recovery structure.

3. The $\beta$-phase precipitation helps increase the electrical conductivity, especially in the recovery structure due to the higher dislocation density. In addition, the electrical conductivity after sensitization is markedly increased and can be employed as indirect evidence of the variation of sensitization.

Acknowledgments: This work was supported by the Ministry of Science and Technology, Taiwan (Grant number MOST 106-2623-E-151-001-D).

Author Contributions: Chia-Chin Chiang designed the study methods and experiments, analyzed the data, and wrote the paper. Ying-Kai Lin, Shing-Hai Wang, Tso-Sheng Hsieh, Liren Tsai, and Ren-Yu Chen conducted the experiments and analyzed the experimental data. 
Conflicts of Interest: The authors declare no conflicts of interest.

\section{References}

1. Sanders, R.E., Jr.; Hollinshead, P.; Simielli, E.A. Industrial development of non-heat treatable aluminum alloys. Mater. Forum 2004, 28, 53-64.

2. Davis, J.R. Corrosion of Aluminum and Aluminum Alloys; ASM International: Metals Park, OH, USA, 1999.

3. Sielski, R.A. SSC-452 Aluminum Structure Design and Fabrication Guide; Ship Structure Committee: Washington, DC, USA, 2007.

4. Sensharma, P.; Collette, M.; Harrington, J. SSC-4 Effect of Welded Properties on Aluminum Structures; Ship Structure Committee: Washington, DC, USA, 2010.

5. Toros, S.; Ozturk, F. Modeling uniaxial, temperature and strain rate dependent behavior of Al-Mg alloys. Comput. Mater. Sci. 2010, 49, 333-339. [CrossRef]

6. Liu, J.; Tan, M.J.; Jarfors, A.E.W.; Aue-u-lan, Y.; Castagne, S. Formability in AA5083 and AA6061 alloys for light weight applications. Mater. Des. 2010, 31, S66-S70. [CrossRef]

7. Picu, R.C.; Vincze, G.; Ozturk, F.; Gracio, J.J.; Barlat, F.; Maniatty, A.M. Strain rate sensitivity of the commercial aluminum alloy AA5182-O. Mater. Sci. Eng. A 2005, 390, 334-343. [CrossRef]

8. Popović, M.; Romhanji, E. Characterization of microstructural changes in an Al-6.8 wt. \% Mg alloy by electrical resistivity measurements. Mater. Sci. Eng. A 2008, 492, 460-467. [CrossRef]

9. Tan, L.; Allen, T.R. Effect of thermomechanical treatment on the corrosion of AA5083. Corros. Sci. 2010, 52, 548-554. [CrossRef]

10. ASTM B928/B928M-09. Standard Specification for High Magnesium Aluminium-Alloy Sheet and Plate for Marine Service; ASTM International: West Conshohocken, PA, USA, 2009.

11. ASTM G67-13. Standard Test Method for Visual Assessment of Exfoliation Corrosion Susceptibility of 5XXX Series Aluminum Alloys; ASTM International: West Conshohocken, PA, USA, 2013.

12. Gupta, R.K.; Zhang, R.; Davies, C.H.J.; Birbilis, N. Influence of Mg content on the sensitization and corrosion of Al-xMg(-Mn) alloys. Corrosion 2013, 69, 1081-1087. [CrossRef]

13. Dix, E.H., Jr.; Anderson, W.A.; Shumaker, M.B. Influence of service temperature on the resistance of wrought aluminum-magnesium alloys to corrosion. Corrosion 1959, 15, 19-26. [CrossRef]

14. Czyryca, E.J.; Hack, H.P.; David, W. Corrosion of Aluminum Alloys in Exfoliation-Resistant Tempers Exposed to Marine Environments for 2 Years; David W. Taylor Naval Ship Research and Development Center: Bethesda, MD, USA, 1974.

15. Searles, J.L.; Gouma, P.I.; Buchheit, R.G. Stress corrosion cracking of sensitized AA5083 (Al-4.5Mg-1.0Mn). Metall. Mater. Trans. A 2001, 32, 2859-2867. [CrossRef]

16. Oguocha, I.N.A.; Adigun, O.J.; Yannacopoulos, S. Effect of sensitization heat treatment on properties of Al-Mg alloy AA5083-H116. J. Mater. Sci. 2008, 43, 4208-4214. [CrossRef]

17. Jones, R.H.; Baer, D.R.; Danielson, M.J.; Vetrano, J.S. Role of Mg in the stress corrosion cracking of an Al-Mg alloy. Metall. Mater. Trans. A 2001, 32, 1699-1711. [CrossRef]

18. Lim, M.L.C.; Scully, J.R.; Kelly, R.G. Intergranular Corrosion Penetration in an Al-Mg Alloy as a Function of Electrochemical and Metallurgical Conditions. Corrosion 2013, 69, 35-47. [CrossRef]

19. Mulazimoglu, M.H.; Drew, R.A.L.; Gruzelski, J.E. Electrical conductivity of aluminium-rich Al-Si-Mg alloys. J. Mater. Sci. Lett. 1989, 8, 297-300. [CrossRef]

(C) 2017 by the authors. Licensee MDPI, Basel, Switzerland. This article is an open access article distributed under the terms and conditions of the Creative Commons Attribution (CC BY) license (http:/ / creativecommons.org/licenses/by/4.0/). 